\title{
Incidence of arrhythmias induced by isometric and dynamic exercise ${ }^{1}$
}

\author{
James M. Atkins, Oscar A. Matthews, C. Gunnar Blomqvist, and Charles B. Mullins \\ From Parkland Memorial Hospital and the Moss Heart Center for Research, Department of Internal Medicine, \\ The University of Texas Health Science Center at Dallas, Southwestern Medical School, Dallas, Texas \\ 75235, U.S.A.
}

The incidence of arrhythmias during isometric sustained handgrip exercise and during dynamic graded bicycle exercise was compared in agroup of 45 patients with various forms of heart disease on no antiarrhythmic therapy. Atrial arrhythmids were equally common during handgrip and bicycle exercise but ventricular arrhythmias were more frequent during handgrip exercise. Of the 45 patients, 38 per cent developed ventricular arrhythmias during isometric exercise, with ventricular tachycardia occurring in 15 per cent. During dynamic exercise 22 per cent of the 45 patients developed ventricular arrhythmias, with ventricular tachycardia occurring in 2 per cent. Patients with coronary artery disease and/or depressed left ventricular function developed twice the incidence of veritricular arrhythmias with isometric than with dynamic exercise Thus, isometric exercise testing is of more value than dynamic exercise testing in unmasking latent ventricular arrhythmias in patients with heart disease.

The circulatory response to dynamic exercise, exemplified by walking and running, has been well characterized both in normal subjects and in patients with various forms of heart disease. However, many activities during daily life primarily involve static or isometric exercise, for example, lifting, carrying, or pushing heavy objects. The physiological aspects of isometric exercise in normal subjects have been studied in detail by Lind, McNicol, and Donald (1966) and Freyschuss (1970), while other studies have been reported in patients with heart disease (Cohn et al., 1973; Ewing et al., 1973; Fisher et al., 1973; Grossman et al., 1973; Haissly et al., 1974; Krayenbuehl et al., 1972; Ludbrook, Karliner, and O'Rourke, 1974; Mullins and Blomqvist, 1973; Quinones et al., 1974; Siegel et al., 1972).

The principal circulatory effects of dynamic and isometric exercise are different. Dynamic exercise causes an increase in heart rate and cardiac output, with a small increase in mean arterial pressure and a significant fall in systemic vascular resistance. Isometric exercise in normal subjects produces an increase in heart rate and cardiac output and a large increase in both systolic and diastolic arterial

Received 8 September 1975.

'Supported by grants from the US Public Health Service, NASA, and the American Heart Association, Texas Affiliate, Inc. pressures, with little or no change in systemic vascular resistance.

The use of isometric exercise as a stress test for evaluation of left ventricular function has recently been explored in this laboratory by Matthews et al. (1974), Mitchell and Wildenthal (1974), and by others (Helfant, de Villa, and Meister, 1971; Jacobs et al., 1970; Kivowitz et al., 1971). We were impressed by the frequent occurrence of arrhythmias during isometric exercise performed in the course of our haemodynamic studies. The present investigation was undertaken to compare the incidence of arrhythmias during and after isometric and dynamic exercise in patients with heart disease.

\section{Patients and methods}

Firty-five patients were continuously monitored by electrocardiography during both isometric and dynamic exercise. The group included 35 men and 10 women, with a mean age of 54.5 years (range 28-78 years). Twenty-three patients had ischaemic heart disease, 18 had valvular heart disease, 3 had primary myocardial disease, and one patient had a residual post-traumatic right bundle-branch block. According to the New York Heart Association classification, 2 patients were in functional class I, 20 in class II, and 23 in class III. Thirty-one patients underwent cardiac catheterizations. No patient was on antiarrhythmic therapy at the time of study, and no patient had ectopic activity at rest during a 5-minute control period. 


\section{A. Isometric exercise (handgrip)}

Isometric exercise was performed using a springloaded handgrip dynamometer. ${ }^{1}$ After determining the force of a maximal voluntary contraction by averaging the results of three different maximal efforts, the patients performed a sustained 25 per cent maximal voluntary contraction for 3 to 5 minutes, with an average duration of 4 minutes. After a 5-minute rest period, the patients performed a 50 per cent maximal voluntary contraction until fatigue set in; the average duration of the 50 per cent voluntary contraction was 1 minute, with a range of 30 seconds to 3 minutes. Care was taken to prevent a Valsalva manoeuvre. Of the 45 patients, 23 were examined by non-invasive techniques, and 22 patients were examined during cardiac catheterization.

The 23 patients examined by non-invasive techniques were monitored with continuous recording of the Frank lead electrocardiogram at a paper speed of $10 \mathrm{~mm} / \mathrm{s}$. Records at paper speeds of 25 or $50 \mathrm{~mm} / \mathrm{s}$ were obtained during rest, the last minute of exercise, immediately after exercise, and 3 minutes after exercise. Indirect brachial artery pressure was recorded every 30 seconds during exercise and every minute during recovery with a semiautomatic device, ${ }^{2}$ with the cuff placed on the resting arm.

Twenty-two patients were examined during cardiac catheterization with continuous and simultaneous recordings of the electrocardiogram, brachial artery pressure, and left ventricular pressure recorded on an Electronics for Medicine recorder at varying paper speeds of 10, 25, and $100 \mathrm{~mm} / \mathrm{s}$. Cardiac output was measured at rest and during the last minute of exercise at each load level by the indicator-dilution method. All cineangiograms were performed after completion of the exercise study. The ejection fraction was determined according to the method of Greene et al. (1967), from single plane (right anterior oblique) cineangiograms.

\section{B. Dynamic or bicycle exercise}

The 45 patients also performed dynamic exercise at progressive loads on a mechanically-braked bicycle ergometer. The duration of exercise at each load was 5 minutes, with a 5-minute rest period between work loads. Selection of the initial work load was based on the patient's history. Patients in functional class I and II began exercise at $300 \mathrm{kpm} / \mathrm{min}$ and patients in class III at $150 \mathrm{kpm} / \mathrm{min}$ or at no load except for the internal resistance of the ergometer. The load was increased in steps of $150 \mathrm{kpm} / \mathrm{min}$. The test was carried to a symptom-limited maximal load unless the patient developed progressive horizontal ST depression of at least $0.1 \mathrm{mV}(1 \mathrm{~mm})$, or unless an increasing number of premature ventricular contractions, multifocal premature ventricular contractions, or runs of two or more occurred. The indications for discontinuing exercise conformed to the standards presented by Rochmis and Blackburn (1971). The technique for monitoring by electrocardiogram was identical to that used during the

${ }^{1}$ C. H. Stoelting Company, Chicago, Illinois.

${ }^{2}$ Narco Systems, Inc., Houston, Texas. non-invasive isometric exercise test. Indirect arterial blood pressure was recorded during the last minute of exercise at each work load as with isometric exercise.

The bicycle test was performed on a separate day within one week of the handgrip test in 22 of the patients. The two tests were done on the same day in 23 patients. Isometric exercise always preceded dynamic exercise, with a rest period of at least one hour between the two tests.

\section{Definition of arrhythmias}

Any patient with an arrhythmia during rest or control periods was eliminated from the study. Ventricular tachycardia was defined as 3 or more successive premature ventricular contractions. A single premature contraction was counted as an arrhythmia.

\section{Results}

Mean data on work load, heart rate, and blood pressure during handgrip and bicycle exercise are presented in Table 1. The mean peak heart rate \pm the standard error with isometric exercise was $86 \pm 2$ beats/minute while it was $122 \pm 4$ beats/ minute with dynamic exercise. The mean peak systolic blood pressure was $179 \pm 6 \mathrm{~mm} \mathrm{Hg} \mathrm{(23.8 \pm}$ $0.8 \mathrm{kPa}$ ) with isometric exercise and $167 \pm 5 \mathrm{mmHg}$ $(22.2 \pm 0.7 \mathrm{kPa})$ with dynamic exercise.

The incidence of various arrhythmias is presented in Table 2 and Fig. 1. Arrhythmias were found more frequently in patients during the isometric exercise test than during the bicycle test, $44 \%$ (20 of 45) of patients compared to $24 \%$ (11 of 45) $\left(\mathrm{P}<0.05^{3}\right)$. The number of patients having arrhythmias with handgrip at the 25 per cent maximal voluntary contraction level was 11 per cent ( 5 of 45$)$.

Premature atrial contractions were equally common with both types of exercise and were seen in 11 per cent ( 5 of 45) of the patients during the handgrip test and in 9 per cent (4 of 45) during the bicycle test. The incidence of ventricular arrhythmias was higher during the handgrip test, 38 per cent (17 of 45) compared with 22 per cent (10 of 45), but the difference was not significant. When single premature ventricular contractions were disregarded, 31 per cent (14 of 45) of patients had 2 or more contractions during the handgrip test compared with 20 per cent ( 9 of 45 ) during the bicycle test. A striking difference was observed in the incidence of ventricular tachycardia, 15 per cent (7 of 45) during the handgrip test and 2 per cent ( 1 of 45) during the bicycle test $(P<0.05)$ (Fig. 1). All patients who had ventricular arrhythmias during the bicycle test also developed premature ventricular contractions and ventricular tachycardia during the handgrip test. Examples of arrhythmias are ${ }^{8} \chi^{2}$. 
TABLE 1 Work load, heart rate, and arterial blood pressure at peak levels of handgrip and bicycle exercise

\begin{tabular}{lcclc}
\hline & & \multicolumn{2}{c}{ Blood pressure (mmHg) } \\
\cline { 4 - 5 } & Work load & Heart rate & Systolic & Diastolic \\
\hline Handgrip exercise & $35 \pm 6$ & $86 \pm 2$ & $179 \pm 6$ & $127 \pm 6$ \\
Bicycle exercise & $391 \pm 31$ & $122 \pm 4$ & $167 \pm 5$ & $94 \pm 3$ \\
\hline
\end{tabular}

$\star$ Work load expressed as kilopond-metres/minute for bicycle exercise and as force in kilograms for isometric exercise. Mean $+S E, n=45$.

Conversion from Traditional Units to SI Units: $1 \mathrm{mmHg} \approx 0.133 \mathrm{kPa}$.

TABLE 2 Incidence of arrhythmias with isometric exercise and dynamic exercise

\begin{tabular}{llllllll}
\hline \multirow{2}{*}{ Diagnosis } & \multicolumn{3}{c}{$\begin{array}{c}\text { Isometric exercise } \\
\text { No.pts }\end{array}$} & PAC's & PVC's & VT & \multicolumn{3}{c}{$\begin{array}{c}\text { Dynamic exercise } \\
\text { PAC's }\end{array}$} & PVC's & VT \\
\hline Ischaemic heart disease & 23 & 3 & 8 & 4 & 1 & 5 & 1 \\
Valvular heart disease & 18 & 0 & 6 & 1 & 2 & 3 & 0 \\
Primary myocardial disease & 3 & 2 & 2 & 1 & 1 & 2 & 0 \\
Cardiac contusion & 1 & 0 & 1 & 1 & 0 & 0 & 0 \\
\hline All diseases & 45 & 5 & 17 & 7 & 4 & 10 & 1 \\
& & $(11 \%)$ & $(38 \%)$ & $(15 \%)$ & $(9 \%)$ & $(22 \%)$ & $(2 \%)$ \\
\hline
\end{tabular}

Abbreviations: PAC, premature atrial contractions; PVC, premature ventricular contractions; VT, ventricular tachycardia.

Four patients had both PAC's and PVC's or VT. Patients with VT are included in the PVC column.

illustrated in Fig. 2, 3, and 4. A comparison of arrhythmias by cardiac diagnoses during isometric and dynamic exercise is illustrated in Fig. 5.

To exclude the possibility that catheter-induced arrhythmias affected our results, the incidence of arrhythmias during handgrip exercise in a group of patients with ischaemic heart disease who were catheterized was compared with a group of patients examined by non-invasive techniques. The patients

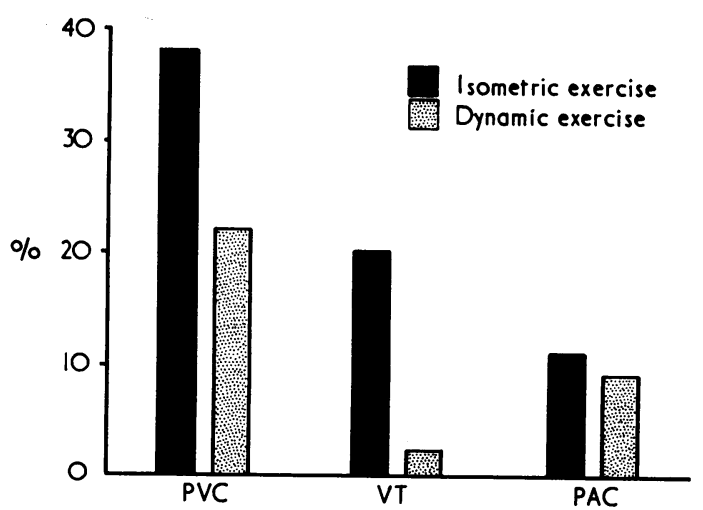

FIG. 1 Incidence of arrhythmias induced by isometric and dynamic exercise stress testing in 45 patients. PVC, premature ventricular contraction; $V T$, ventricular tachycardia; $P A C$, premature atrial contraction. were matched with respect to age and the severity of angina. Five of $10(50 \%)$ patients studied during cardiac catheterization had arrhythmias compared with 30 per cent ( 4 of 13) in the group studied by indirect techniques. This difference was not significant between invasive and non-invasive techniques $(P>0 \cdot 2)$. Four episodes of ventricular tachycardia were seen in the catheterized patients and 3 episodes were seen in the patients studied by non-invasive methods. All patients were excluded who, during catheterization, had arrhythmias at rest or during control periods with the catheters in place.

Twenty-one patients had left ventricular cineangiograms. Patients with ventricular arrhythmias had a mean ejection fraction of 46 per cent, suggesting that arrhythmias are more common with deteriorating left ventricular function.

Nine patients had ischaemic heart disease documented by coronary cineangiography. Ventricular arrhythmias occurred in 3 of 4 patients with triple-vessel disease, 1 of 3 patients with 2vessel disease, and 1 of 2 patients with singlevessel disease, suggesting that arrhythmias were more common in patients with more severe coronary artery disease; however, the number of patients is too small for this trend to be significant.

Individual heart rate, blood pressure, and heart rate-systolic blood pressure product data in a subgroup of 11 patients with angina pectoris and ST 


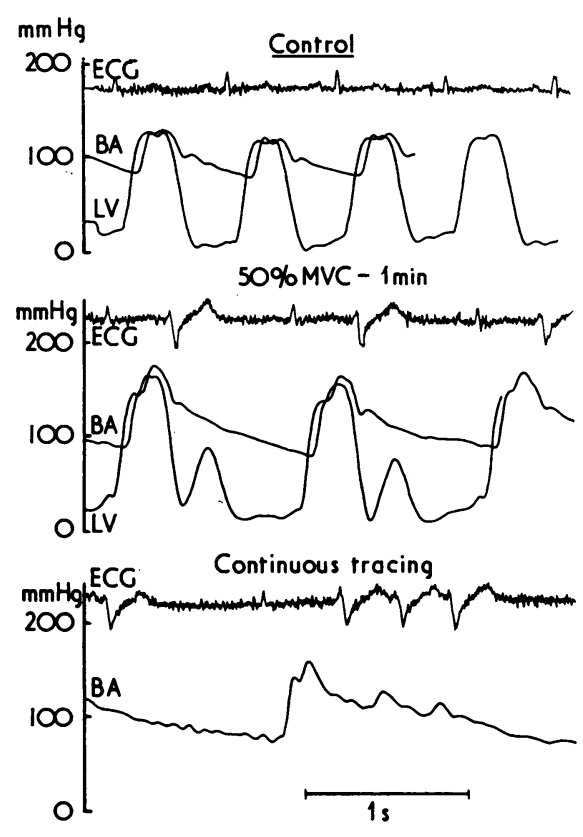

FIG. 2 An example of ventricular arrhythmias occurring during isometric stress testing during cardiac catheterization. No arrhythmia was present before testing. The handgrip was released and the patient returned to normal sinus rhythm. $B A$, brachial artery pressure; $L V$, left ventricular pressure; $M V C$, maximal voluntary contraction; 50 per cent MVC 1 min, 50 per cent maximal voluntary handgrip contraction held for 1 minute. depressions during bicycle exercise are presented in Fig. 6. Mean maximal heart rate was 84 during handgrip exercise and 118 during bicycle exercise. Peak systolic blood pressure was slightly higher during handgrip, $188 \mathrm{mmHg}(25.0 \mathrm{kPa})$, than during bicycle exercise, $175 \mathrm{mmHg}(23.3 \mathrm{kPa})$. The heart rate-systolic blood pressure product $/ 100$ was higher during bicycle exercise, 207, compared with 158 with isometric exercise.

\section{Discussion}

Ventricular arrhythmias are frequently seen in patients undergoing exercise stress tests using dynamic exercise methods. We found that 22 per cent of the patients with heart disease in this study developed arrhythmias, a similar incidence to that of other reported series.

Kosowsky et al. (1971) reported 26 per cent ventricular arrhythmias during a treadmill test in patients who were free from arrhythmias at rest. Other investigators have reported ventricular arrhythmias in 10 to 39 per cent of cardiac patients undergoing treadmill or bicycle exercise tests, but quantitative comparison between series is difficult because of the differences with respect to patients, exercise test modes, monitoring techniques, diagnostic criteria, and antiarrhythmic therapy.

Ventricular arrhythmias are rare among young normal subjects during dynamic exercise but the incidence increases sharply with increasing age. Strandell (1963) found at least occasional premature ventricular contractions in 32 per cent of apparent

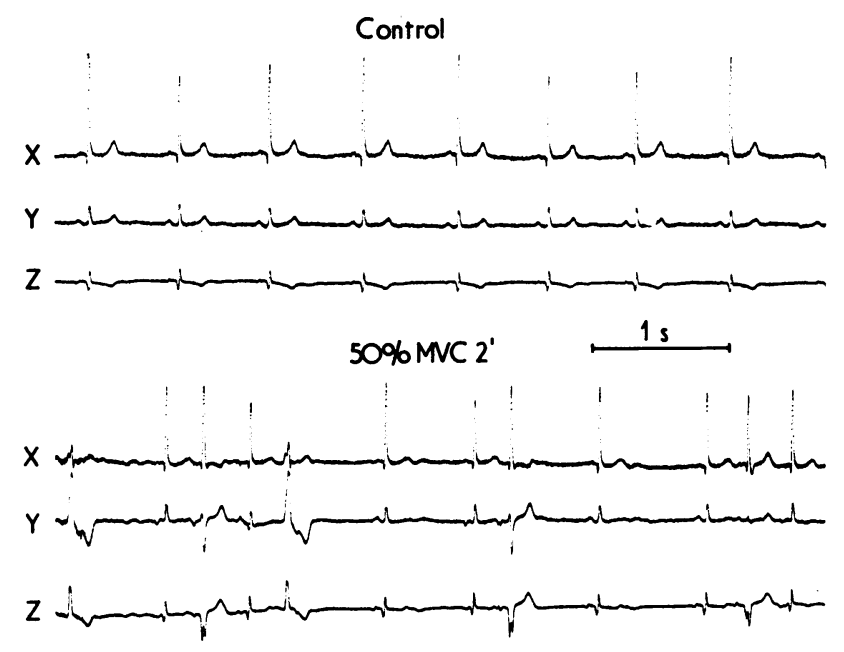

FIG. 3 An example of arrhythmias developing during isometric stress testing using xyz Frank lead system. Multifocal ventricular as well as supraventricular arrhythmias are present. 50 per cent MVC 2', 50 per cent maximal voluntary handgrip contraction held for 2 minutes. 
Control

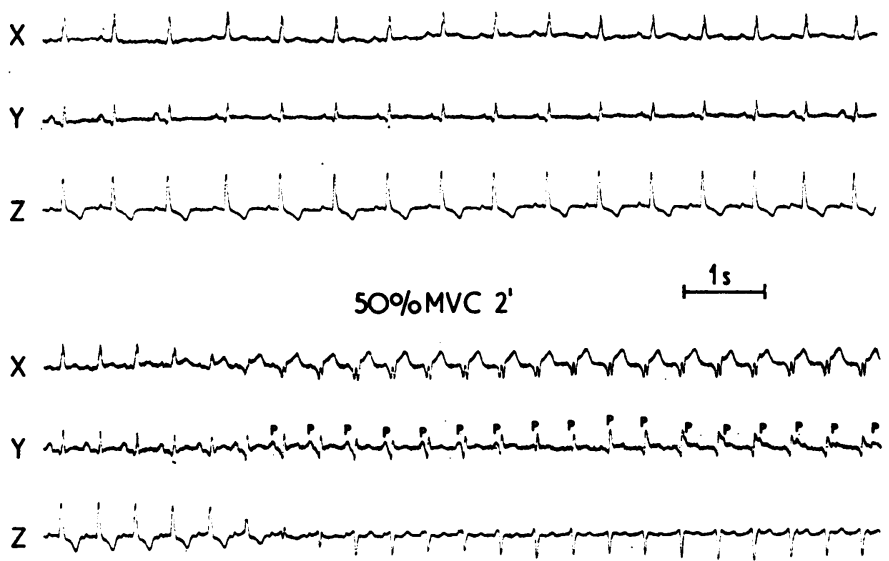

FIG. 4 An example of ventricular tachycardia occurring during isometric stress testing. See Fig. 3 for abbreviations.

healthy men, age 60 to 83, who performed maximal or near-maximal bicycle exercise. Ellestad et al. (1969) saw 9 cases of ventricular tachycardia among 1000 asymptomatic middle-aged subjects during or after a progressive treadmill test. Similar findings have also been reported by Gooch and McConnell (1970).

The surprising finding in this study was the high incidence of ventricular arrhythmias during isometric stress testing. Thirty-eight per cent of the

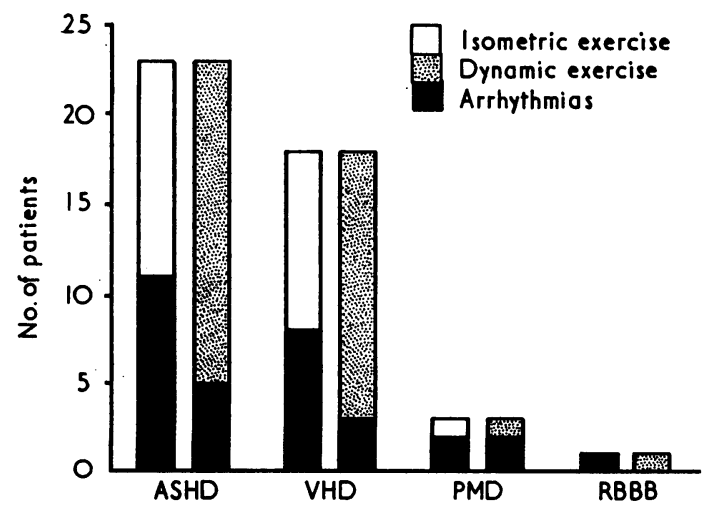

F I G. 5 Comparison of arrhythmias by cardiac diagnoses during isometric and dynamic exercise. $A S H D$, ischaemic heart disease; VHD, valvular heart disease; $P M D$, primary myocardial disease; $R B B B$, right bundle-branch block caused by a cardiac contusion.
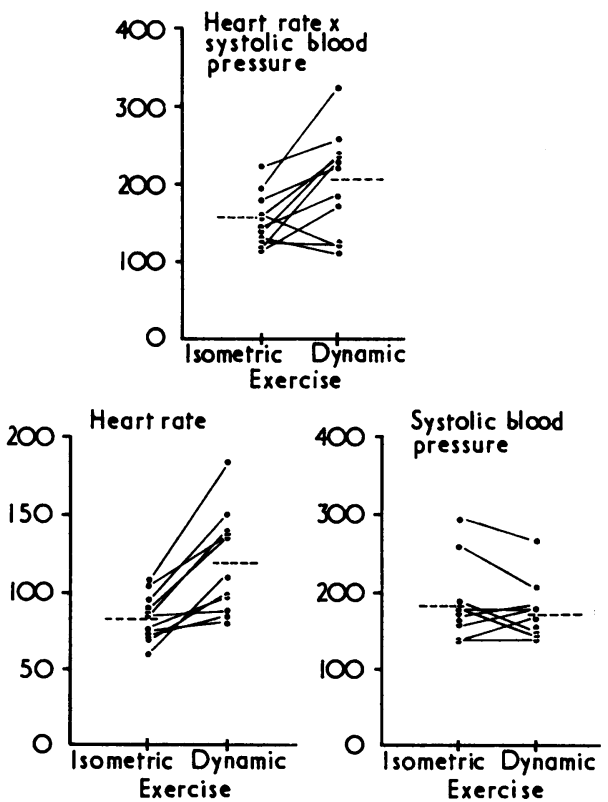

F I G. 6 Heart rates and systolic blood pressures in 11 patients with angina pectoris during isometric and dynamic exercise. The solid lines connecting dots represent individual patients. The dashed lines are the group means. In the upper panel are plotted the maximal heart rate $\times$ systolic blood pressure/100 during both isometric and dynamic exercise. In the lower left-hand panel are plotted the maximal heart rates during both isometric and dynamic exercise. 
patients developed ventricular arrhythmias, a 16 per cent increase above the incidence with dynamic testing. Arrhythmias with isometric exercise in normal subjects are unusual. We have seen only a single premature ventricular contraction in 2 of 60 normal subjects during isometric stress testing. Other reports (Cohn et al., 1973; Fisher et al., 1973; Grossman et al., 1973; Haissly et al., 1974; Helfant et al., 1971; Kivowitz et al., 1971; Krayenbuehl et al., 1972; Ludbrook et al., 1974; Matthews et al., 1974; Mitchell and Wildenthal, 1974; Mullins and Blomqvist, 1973; Prakash et al., 1972; Quinones et al., 1974; Siegal et al., 1972) have indicated only occasional arrhythmias; however, these studies were not designed to look specifically for arrhythmias, and continuous electrocardiographic recordings were not always made. Furthermore, no comments were made regarding the use of antiarrhythmic therapy before exercise testing.

In this series all patients who developed arrhythmias did so at 50 per cent maximal voluntary contraction, a higher isometric stress than used by other investigators. The incidence of ventricular arrhythmias was only 11 per cent in this series at 25 per cent maximal voluntary contraction.

The incidence of ventricular arrhythmias and especially ventricular tachycardia was high in patients with ischaemic heart disease and in those with abnormal ventricular function. Those patients with depressed ejection fraction and those with severe coronary disease on coronary angiography had a 50 per cent incidence of ventricular arrhythmias during isometric stress testing.

The reasons for the high incidence of ventricular arrhythmias during isometric exercise in patients with heart disease is not clear. A more intense sympathetic drive during isometric than during dynamic exercise is a possible but unlikely explanation. Physiological studies by Lind et al. (1966) and by Freyschuss (1970) suggest that the heart rate increase during isometric exercise is primarily mediated by vagal withdrawal. The rate acceleration during dynamic exercise at low work load levels is also primarily the result of vagal withdrawal, but sympathetic stimulation becomes increasingly important at higher loads (Robinson et al., 1966). The arrhythmia-suppressing effect of an increased heart rate is well known, i.e. sinus tachycardia overdrive of the ventricular arrhythmia. The occurrence of chest pain and ischaemic ST depressions more frequently during dynamic exercise in the patients with ischaemic heart disease and the peak heart rates and heart rate-systolic blood pressure products during exercise indicate that peak myocardial oxygen demand was higher during dynamic exercise. The higher incidence of ventricular arrhythmias during isometric exercise when compared with dynamic exercise may be related to a lower heart rate at any given level of cardiac work (Fig. 6).

The high incidence of serious ventricular arrhythmias with isometric stress testing in this study suggests that stress tests based on isometric exercise should be performed where facilities for monitoring and resuscitation are available. It also seems prudent to discourage activities requiring heavy isometric exercise in patients with heart disease because of the chance of sudden death induced by ventricular tachycardia or fibrillation.

\section{References}

Cohn, P. F., Horn, H. R., Teichholz, L. E., Kreulen, T. H., Herman, M. V., and Gorlin, R. (1973). Effects of angiographic contrast medium on left ventricular function in coronary artery disease. American fournal of Cardiology, 32, 21.

Ellestad, M. H., Allen, W., Wan, M. C. K., and Kemp, G. L. (1969). Maximal treadmill stress testing for cardiovascular evaluation. Circulation, 39, 517.

Ewing, D. J., Irving, J. B., Kerr, F., and Kirby, B. J. (1973). Static exercise in untreated systemic hypertension. British Heart fournal, 35, 413.

Fisher, M. L., Nutter, D. O., Jacobs, W., and Schlant, R. C. (1973). Haemodynamic responses to isometric exercise (handgrip) in patients with heart disease. British Heart fournal, 35, 422.

Freyschuss, U. (1970). Cardiovascular adjustment to somatomotor activation. Acta Physiologica Scandinavica, Suppl. 342.

Gooch, A. S., and McConnell, D. (1970). Analysis of transient arrhythmias and conduction disturbances occurring during submaximal treadmill exercise testing. Progress in Cardiovascular Diseases, 13, 293.

Greene, D. G., Carlisle, R., Grant, C., and Bunnell, I. L. (1967). Estimation of left ventricular volume by one-plane cineangiography. Circulation, 35, 61.

Grossman, W., McLaurin, L. P., Saltz, S. B., Paraskos, J. A., Dalen, J. E., and Dexter, L. (1973). Changes in the inotropic state of the left ventricle during isometric exercise. British Heart fournal, 35, 697.

Haissly, J. C., Messin, R., Degre, S., Vandermoten, P., Demaret, B., and Denolin, H. (1974). Comparative response to isometric (static) and dynamic exercise tests in coronary disease. American fournal of Cardiology, 33, 791 .

Helfant, R. H., deVilla, M. A., and Meister, S. G. (1971). Effect of sustained isometric handgrip exercise on left ventricular performance. Circulation, 44, 982.

Jacobs, W. F., Nutter, D. O., Siegal, W., Schlant, R. C., and Hurst, J. W. (1970). Hemodynamic responses to isometric handgrip in patients with heart disease (abstract). Circulation, 42, Suppl 3, 169.

Kivowitz, C., Parmley, W. W., Donoso, R., Marcus, H., Ganz, W., and Swan, H. J. C. (1971). Effects of isometric exercise on cardiac performance: the grip test. Circulation, 44, 994.

Kosowsky, B. D., Lown, B., Whiting, R., and Guiney, T. (1971). Occurrence of ventricular arrhythmias with exercise as compared to monitoring. Circulation, 44, 826.

Krayenbuehl, H. P., Rutishauser, W., Schoenbeck, M., and Amende, I. (1972). Evaluation of left ventricular function from isovolumic pressure measurements during isometric exercise. American fournal of Cardiology, 29, 323. 
Lind, A. R., McNicol, G. W., and Donald, K. W. (1966). Circulatory adjustments to sustained (static) muscular activity. In Physical Activity in Health and Disease, p. 38. Ed. by $\mathrm{K}$. Evang and K. L. Andersen. Universitatsforlaget, Oslo.

Ludbrook, P., Karliner, J. S., and O'Rourke, R. A. (1974). Effects of submaximal isometric handgrip on left ventricular size and wall motion. American fournal of Cardiology, 33, 30.

Matthews, O. A., Blomqvist, C. G., Cohen, L. S., and Mullins, C. B. (1974). Left ventricular function during isometric exercise (handgrip): significance of an atrial gallop $\left(\mathrm{S}_{4}\right)$. American Heart fournal, 88, 686.

Mitchell, J. H., and Wildenthal, K. (1974). Static (isometric) exercise and the heart: physiological and clinical considerations. Annual Review of Medicine, 25, 369.

Mullins, C. B., and Blomqvist, G. (1973). Isometric exercise and the cardiac patient. Texas Medicine, 69, 53.

Prakash, R., Parmley, W. W., Dikshit, K., Forrester, J., and Swan, H. J. C. (1972). The effects of isometric handgrip stress in patients with acute myocardial infarction (abstract). Clinical Research, 20, 209.

Quinones, M. A., Gaasch, W. H., Waisser, E., Thiel, H. G., and Alexander, J. K. (1974). An analysis of the left ventri- cular response to isometric exercise. American Heart Fournal, 88, 29.

Robinson, B. F., Epstein, S. E., Beiser, G. D., and Braunwald, E. (1966). Control of heart rate by the autonomic nervous system: studies in man on the interrelationship between baroreceptor mechanisms and exercise. Circulation Research, 19, 400.

Rochmis, P., and Blackburn, H. (1971). Exercise tests: a survey of procedures, safety, and litigation experience in approximately 170,000 tests. Fournal of the American Medical Association, 217, 1061.

Siegel, W., Gilbert, C. A., Nutter, D. O., Schlant, R. C., and Hurst, J. W. (1972). Use of isometric handgrip for the indirect assessment of left ventricular function in patients with coronary atherosclerotic heart disease. American Fournal of Cardiology, 30, 48.

Strandell, T. (1963). Electrocardiographic findings at rest, during and after exercise in healthy old men compared with young men. Acta Medica Scandinavica, 174, 479.

Requests for reprints to Dr. James M. Atkins, Cardiopulmonary H8-116, 5323 Harry Hines Boulezard Dallas, Texas 75235, U.S.A. 